\author{
Suzanne Heemskerk \\ Frank M. P. van Haren \\ Norbert A. Foudraine \\ Wilbert H. M. Peters \\ Johannes G. van der Hoeven \\ Frans G. M. Russel \\ Rosalinde Masereeuw \\ Peter Pickkers
}

\section{Short-term beneficial effects of methylene blue on kidney damage in septic shock patients}

Received: 24 January 2007

Accepted: 31 August 2007

Published online: 10 October 2007

(C) Springer-Verlag 2007

Electronic supplementary material The online version of this article (doi:10.1007/s00134-007-0867-9) contains supplementary material, which is available to authorized users.

S. H. was supported by a grant from The Netherlands Organization for Scientific Research; F. v. H. was supported by a grant from the Waikato Medical Research Foundation; P. P. is recipient of a Clinical Fellowship grant of The Netherlands Organization for Scientific Research.

S. Heemskerk · F. G. M. Russel •

R. Masereeuw

Radboud University, Nijmegen Medical

Centre, Department of Pharmacology and

Toxicology, Nijmegen Center for Molecular

Life Sciences,

6500 HB Nijmegen, The Netherlands

F. M. P. van Haren

Waikato Hospital, Department of Intensive

Care Medicine,

Hamilton, New Zealand

N. A. Foudraine

VieCuri Medical Centre, Department of Intensive Care Medicine,

Venlo, The Netherlands
W. H. M. Peters

Radboud University, Nijmegen Medical Centre, Department of Gastroenterology, Nijmegen, The Netherlands

J. G. van der Hoeven · P. Pickkers ( Radboud University, Nijmegen Medical Centre, Department of Intensive Care Medicine,

P.O. Box 9101, 6500 HB Nijmegen,

The Netherlands

e-mail: p.pickkers@ic.umcn.nl

Tel.: +31-24-3617273

Fax: +31-24-3541612

Abstract Objective: We previously demonstrated that upregulation of renal inducible nitric oxide synthase (iNOS) is associated with proximal tubule injury during systemic inflammation in humans. In this study we investigated the short-term effect of methylene blue (MB), an inhibitor of the NO pathway, on kidney damage and function in septic shock patients. Design and setting: A prospective clinical study conducted in an intensive care unit. Patients: Nine patients (four men, five women, mean age $71 \pm 3$ years) with confirmed or suspected bacterial infection and with refractory septic shock defined as a mean arterial pressure $\leq 70 \mathrm{mmHg}$ despite norepinephrine infusion $\geq 0.2 \mu \mathrm{g} / \mathrm{kg}$ per minute. Interventions: A $4 \mathrm{~h}$ continuous intravenous infusion of $1 \mathrm{mg} / \mathrm{kg}$ MB per hour. Measurements and results: The urinary excretion of $\mathrm{NO}$ metabolites decreased with median $90 \%$ (range $75-95 \%$ ) from baseline to $6 \mathrm{~h}$ after MB administration. The first $24 \mathrm{~h}$ creatinine clearance improved by $51 \%$ (18-173\%) after MB treatment but was still strongly impaired. During the first $6 \mathrm{~h}$ after the start of MB treatment both the urinary excretion of cytosolic glutathione $S$-transferase A1-1 and P1-1, markers for proximal and distal tubule damage, respectively, decreased by $45 \%(10-70 \%)$ and $70 \%$ (40-85) vs. baseline. After termination of the MB infusion the NO metabolites and markers of tubular injury returned to pretreatment levels. Conclusions: In septic patients with refractory shock short-term infusion of $\mathrm{MB}$ is associated with a decrease in NO production and an attenuation of the urinary excretion of renal tubular injury markers.

Keywords Inducible nitric oxide synthase expression - Acute kidney injury . Glutathione $S$-Transferase . Nitric oxide metabolites 


\section{Introduction}

Refractory septic shock remains the major cause of death in noncoronary intensive care units, especially when accompanied by multiple organ failure, with an estimated mortality rate of 50-60\% [1]. The incidence of acute renal failure in refractory septic shock is approx. 40-50\% [2]. Nitric oxide has emerged as an important contributory factor to the pathogenesis of septic shock. We previously demonstrated that induction of renal NO is associated with proximal tubule injury during systemic inflammation in humans [3]. NO stimulates soluble guanylate cyclase (sGC) by binding to its heme moiety, which generates cyclic guanosine monophosphate (cGMP) [4]. In the kidney NO and cGMP production are associated with lipopolysaccharide-induced renal proximal tubular cell toxicity [5]. Selective sGC inhibition during septic shock in rats resulted in an attenuation of renal dysfunction [6], indicating that blocking sGC may be a potential therapeutic strategy to treat septic shock-associated renal failure.

Methylene blue (MB) binds to sGC, blocks cGMP production and has the ability to scavenge $\mathrm{NO}$ and to inhibit NO synthases $[7,8]$. Although several controlled and uncontrolled clinical studies showed beneficial effects of MB on the hemodynamic instability during septic shock (reviewed in [9]), there are no studies on the putative protective renal effects. We examined the short-term effects of continuous infusion of low-dose MB ( $1 \mathrm{mg} / \mathrm{kg}$ per hour) in patients with septic shock on urinary excretion of the acute kidney injury markers, cytosolic glutathione $S$-transferases (GSTs) present in proximal tubule (GSTA1-1) and distal tubule (GSTP1-1) [10].

\section{Material and methods}

Patients

Nine patients received a $4 \mathrm{~h}$ continuous infusion of $1 \mathrm{mg} / \mathrm{kg}$ per hour MB (1\% w/v) provided by the VieCuri Medical Center pharmacy (for inclusion criteria see Electronic Supplementary Material, ESM). Arterial blood and catheterized urine were collected at several time points during the first $24 \mathrm{~h}$. Clinical parameters, the severity of illness using Acute Physiology and Chronic Health Evaluation II (APACHE II), and Sepsis-Related Organ Failure Assessment (SOFA) were recorded.

\section{Chemical assays}

Biochemical parameters were determined by routine clinical chemistry. Hemoglobin, methemoglobin, and bilirubin were measured to assess possible side effects of $\mathrm{MB}$, such as hemolytic anemia and methemoglobine-
Fig. 1 NO metabolites in plasma and urine and the urinary excretion of tubular injury markers glutathione $S$-transferase (GST) A1-1 and P1-1. NO metabolite levels in plasma (a, $n=9)$ and urine $(\mathbf{b}, n=8)$ and levels of GSTA1-1 (c, proximal tubule, $n=8)$ and GSTP1-1 (d, distal tubule, $n=8$ ) were measured in urine at various times after $\mathrm{MB}$ administration in septic shock patients. The urinary excretion of NO metabolites and GSTs was corrected for creatinine excretion. Data are expressed as median with $25-75 \%$ range and analyzed by analysis of variance with repeated measures over the two time periods; $* p<0.05$ vs. baseline, $\# p<0.05$ vs. $6 \mathrm{~h}$ after $\mathrm{MB}$ treatment
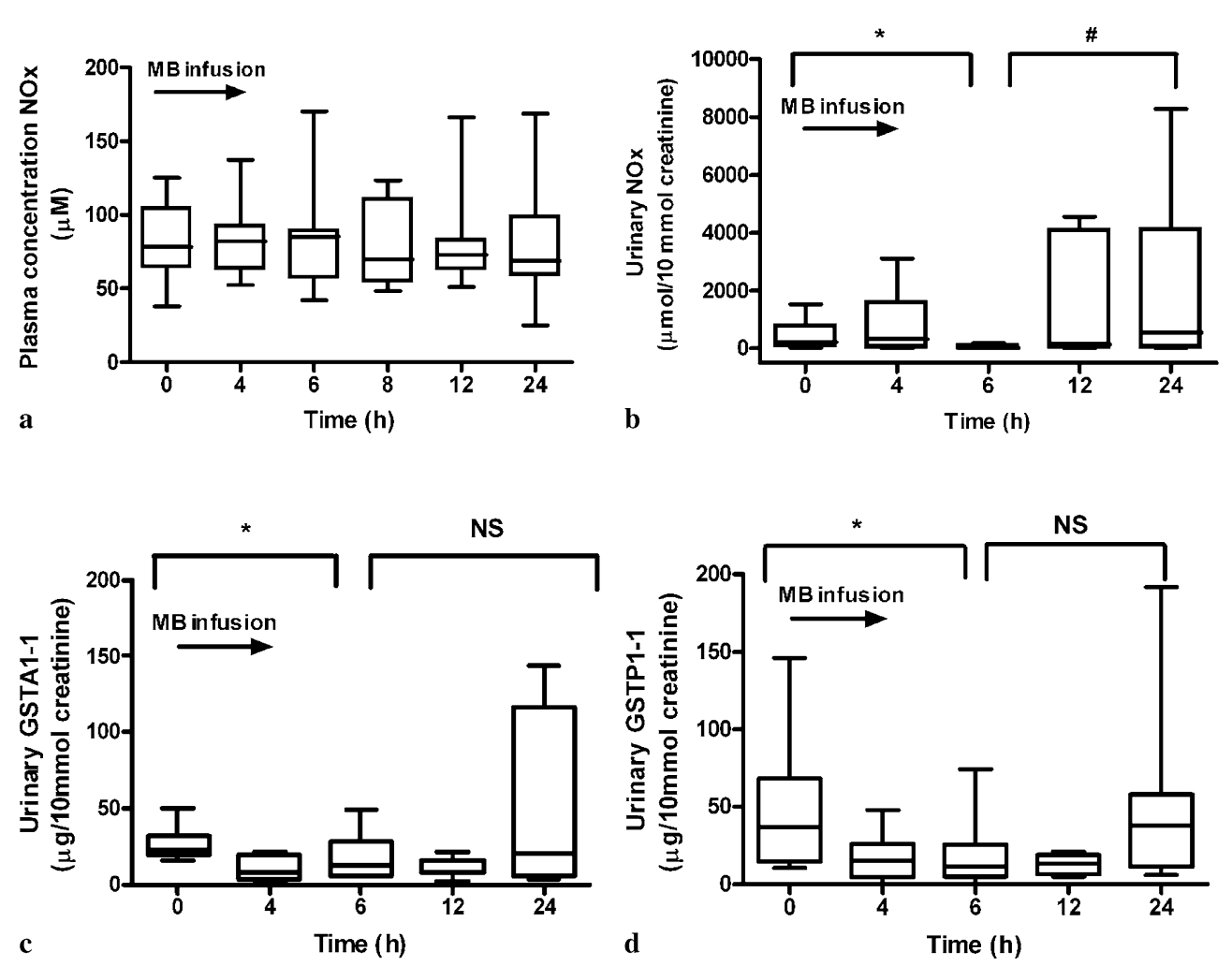
mia [11-13]. Total amount of the stable NO metabolites, nitrate and nitrite, measure of NO radicals production, and the amounts of GSTA1-1 and GSTP1-1 in urine were assayed as described [3]. The blue color in urine due to MB excretion did not affect the chemical assays.

\section{Statistical analysis}

Values are given as mean \pm S.E. or as median $(25-75 \%$ range) depending on their distribution. Differences between experimental groups were tested by analysis of variances for repeated measures. A two-tailed $p$-value less than 0.05 was considered statistically significant.

\section{Results}

Patients

Seven patients ultimately died in the intensive care unit, one of refractory shock (within $12 \mathrm{~h}$ ) and six patients because of multiple organ failure. In the latter group two died within 7 days and the remaining four within 28 days after intervention. The mean calculated predicted mortality rate was $61 \%$, and all patients had at least three organ failures, reflecting a mean SOFA score of $11.1 \pm 0.9$. The median stay at the intensive care unit was 16 days (range 7-24); the two survivors stayed 89 days (52-121) in hospital. Pathogenic organisms isolated by culture and site of infection are illustrated in the ESM Median C-reactive protein was $178 \mathrm{mg} / \mathrm{l}(118-189)$; all patients had lactic acidemia (median $2.7 \mathrm{mmol} / \mathrm{l}$, range $2.1-3.7)$ and thrombocytopenia $\left(68 \times 10^{9} / 1,50-104\right)$. The median MAP increased slightly by $5 \mathrm{mmHg}(2-11)$ from $69(65-70)$ at baseline to $74(68-82) 3 \mathrm{~h}$ after the start of

Table 1 Kidney function parameters of septic shock patients $(n=8)$ treated with $\mathrm{MB}$

\begin{tabular}{lll}
\hline & Median & Range \\
\hline Total urine volume, 0-24 h (ml) & 495 & $169-885$ \\
Protein excretion, 0-24 h (mg/day) & 342 & $245-434$ \\
Creatinine clearance (ml/min) & & \\
$\quad$ Baseline & 8.2 & $4.2-17.4$ \\
$\quad$ 24 h & $10.6^{*}$ & $9.6-14.8$ \\
Blood urea nitrogen & & \\
$\quad$ Baseline & 17.8 & $10.8-20.0$ \\
$\quad$ 24 h & 17.3 & $10.4-22.5$ \\
Fractional excretion of sodium $(\%)$ & & \\
$\quad>2 \%$ & & \\
$\quad$ Baseline $(n=0)$ & 3.1 & - \\
$\quad 24 \mathrm{~h}(n=3)$ & & \\
$\quad<1 \%$ & 0.6 & $0.3-0.7$ \\
$\quad$ Baseline $(n=8)$ & 0.4 & $0.2-0.5$ \\
$\quad 24 \mathrm{~h}(n=5)$ & & \\
\hline
\end{tabular}

$p<0.05$ vs. baseline
MB $(p<0.05)$ with no change in norepinephrine infusion rate. Methemoglobinemia or hemolytic anemia did not develop after MB (data not shown). All MB-treated patients showed blue-coloring of urine and skin.

\section{MB attenuates NO formation}

The concentration NO metabolites in plasma was higher in septic shock patients than in to healthy volunteers [3] but did not change after MB administration (Fig. 1a). In contrast, MB significantly attenuated the urinary excretion of NO metabolites by a median $90 \%(75-95 \%, p<0.05)$ from baseline ( $233 \mu \mathrm{mol} / \mathrm{mmol}$ creatinine, $112-536)$ to $6 \mathrm{~h}$ (37, 10-87) after the start of MB (Fig. 1b). At 4h the MB infusion was stopped, after which the median excretion of urinary NO metabolites increased by $135 \%$ (65-795\%, $p<0.05$ ) within 6-24 h after MB treatment (Fig. 1b).

\section{MB attenuates kidney damage}

All patients showed impaired renal function with oliguria and mild proteinuria (Table 1). One patient suffered from anuria during the first day. Six patients required continuous venovenous hemofiltration renal replacement therapy with a flow of $35 \mathrm{ml} / \mathrm{kg}$ (for median 8.5 days, 4-13), of which 3 during the MB infusion. The creatinine clearance improved by median $51 \%(18-173 \%, p<0.05)$ during the first $24 \mathrm{~h}$ after MB but was still strongly impaired (Table 1 ). The urinary excretion of both GSTA1-1 and GSTP1-1 was elevated in all septic shock patients, indicating both proximal and distal renal tubule damage. During the first $6 \mathrm{~h}$ of MB urinary excretion of GSTA1-1 and GSTP1-1 was attenuated by median $45 \%(10-70 \%)$ and $70 \%(40-85 \%)$ vs. baseline (Fig. 1c, d, $p<0.05$ ). After ending MB infusion urinary excretion of GSTA1-1 and GSTP1-1 increased again, although not significantly (Fig. 1c, d).

\section{Discussion}

Several clinical studies in septic shock patients have investigated the effects of MB on the heart, vascular wall, and lungs [9]. This is the first report demonstrating that MB attenuates kidney damage in human septic shock. To determine the effect of NO pathway inhibition on renal damage we examined the urinary excretion of early tubular injury markers and found that MB inhibited the NO pathway and preserved the integrity of renal tubules. After termination of MB infusion these parameters returned to their elevated pretreatment levels. Both plasma concentrations (more than twofold) and urinary NO metabolites levels in our septic shock patients were much higher than in healthy volunteers, as demonstrated earlier [3]. Hydrocortisone may have inhibited iNOS 
activation, however, the patients received a continuous infusion of hydrocortisone that started before MB infusion and continued during the $24 \mathrm{~h}$ period. Therefore the observation that urinary NO metabolite excretion was attenuated only in the first $6 \mathrm{~h}$ after the start of MB suggests that this effect is not related to steroids. Although urinary NO metabolite excretion was attenuated, we did not find a reduction in plasma NO metabolites. This is in contrast with an earlier report, in which patients received a bolus injection of MB prior to the continuous infusion [14].

Renal failure in septic shock patients is a complex and multifactorial disease process. During septic shock the systemic vasodilation increases renal sympathetic activity and angiotensin concentration which results in intrarenal vasoconstriction with sodium and water retention and decreased glomerular filtration rate [2]. We previously demonstrated that induction of renal iNOS, constitutively expressed in the kidney [15], is associated with proximal tubule injury during systemic inflammation in humans [3]. As a result of its active secretory transport function and role in urine concentration, the proximal tubule is a susceptible target and often the first site of damage [16]. Therefore inhibition of peroxynitrite formation from excessively produced NO and superoxide [17] by MB may be beneficial for the kidney during septic shock, possibly explained by the local accumulation of MB in renal proximal tubules [18]. Global hemodynamic variables can influence renal function, however, only a small but statistically significant increase was found for mean arterial pressure, whereas other global hemodynamic parameters did not change during $\mathrm{MB}$ treatment.
Since the detailed nature of our investigation, obviously these methods are not feasible in a large-scale clinical intervention study. The most elegant way to examine the effects of MB would be in a randomized, placebo-controlled cross-over study. However, with such critically ill patients this design may be considered unethical. We deliberately chose a subgroup of severe septic shock patients with a high chance of sepsis-induced renal damage for two reasons: first, this is the group of patients in which MB is used as a "last resort therapy" and, second, to demonstrate the putative beneficial effects of $\mathrm{MB}$ on renal damage. With an estimated standard deviation of $36 \%$ in urinary GST excretion, 80 patients would be needed to demonstrate with $80 \%$ power a $10 \%$ reduction in renal injury. This number of patients was not feasible for our investigations. Therefore we decided to determine the parameters before, during and after MB infusion during a $24 \mathrm{~h}$ period, which allows each patient to serve as own control. Because of the observational nature and limited size of the present study and the heterogeneity of the patient population, our findings warrant conformation on hard endpoints by a larger clinical trial. However, in our view, first a long-term study is necessary to assess the safety of chronic MB administration in septic patients with refractory shock. Promising effects of MB were found in a trial with vasoplegic patients after cardiac surgery treated with MB [19], in which a reduction in both mortality and incidence of renal failure was observed.

In conclusion, short-term infusion of MB in septic patients with refractory shock, is associated with a decrease in NO production and an attenuation of the urinary excretion of renal tubular injury markers.

\section{References}

1. Alberti C, Brun-Buisson C, Goodman SV, Guidici D, Granton J, Moreno R, Smithies M, Thomas O, Artigas A, Le G Jr (2003) Influence of systemic inflammatory response syndrome and sepsis on outcome of critically ill infected patients. Am J Respir Crit Care Med 168:77-84

2. Schrier RW, Wang W (2004) Acute renal failure and sepsis. N Engl J Med 351:159-169

3. Heemskerk S, Pickkers P, Bouw MP, Draisma A, van der Hoeven JG, Peters WH, Smits P, Russel FG, Masereeuw R (2006) Up-regulation of renal iNOS during human endotoxemia and sepsis is associated with proximal tubule injury. Clin $\mathrm{J}$ Am Soc Nephrol 1:853-862
4. Vincent JL, Zhang H, Szabo C, Preiser JC (2000) Effects of nitric oxide in septic shock. Am J Respir Crit Care Med 161:1781-1785

5. Traylor LA, Proksch JW, Beanum VC, Mayeux PR (1996) Nitric oxide generation by renal proximal tubules: role of nitric oxide in the cytotoxicity of lipid A. J Pharmacol Exp Ther 279:91-96

6. Zacharowski K, Berkels R, Olbrich A, Chatterjee PK, Cuzzocrea S, Foster SJ, Thiemermann C (2001) The selective guanylate cyclase inhibitor ODQ reduces multiple organ injury in rodent models of Grampositive and Gram-negative shock. Crit Care Med 29:1599-1608

7. Mayer B, Brunner F, Schmidt K (1993) Inhibition of nitric oxide synthesis by methylene blue. Biochem Pharmacol 45:367-374
8. Marczin N, Ryan US, Catravas JD (1992) Methylene blue inhibits nitrovasodilator- and endotheliumderived relaxing factor-induced cyclic GMP accumulation in cultured pulmonary arterial smooth muscle cells via generation of superoxide anion. J Pharmacol Exp Ther 263:170-179

9. Kwok ES, Howes D (2006) Use of methylene blue in sepsis: a systematic review. J Intensive Care Med 21:359-363

10. Bagshaw SM, Langenberg C, Haase M, Wan L, May CN, Bellomo R (2007) Urinary biomarkers in septic acute kidney injury. Intensive Care Med, pub ahead of print

11. Levy MM, Fink MP, Marshall JC, Abraham E, Angus D, Cook D, Cohen J, Opal SM, Vincent JL, Ramsay G (2003) $2001 \mathrm{SCCM} / \mathrm{ESICM} / \mathrm{ACCP} / \mathrm{ATS} / \mathrm{SIS}$ International Sepsis Definitions Conference. Intensive Care Med 29:530-538 
12. Kirsch IR, Cohen HJ (1980) Heinz body hemolytic anemia from the use of methylene blue in neonates. J Pediatr 96:276-278

13. Curry S (1982) Methemoglobinemia. Ann Emerg Med 11:214-221

14. Kirov MY, Evgenov OV, Evgenov NV, Egorina EM, Sovershaev MA, Sveinbjornsson B, Nedashkovsky EV, Bjertnaes LJ (2001) Infusion of methylene blue in human septic shock: a pilot, randomized, controlled study. Crit Care Med 29:1860-1867
15. Ortiz PA, Garvin JL (2003) Cardiovascular and renal control in NOS-deficient mouse models. Am J Physiol Regul Integr Comp Physiol 284:R628-R638

16. Masereeuw R, Russel FG (2001) Mechanisms and clinical implications of renal drug excretion. Drug Metab Rev 33:299-351

17. Beckman JS, Koppenol WH (1996) Nitric oxide, superoxide, and peroxynitrite: the good, the bad, and ugly. Am J Physiol 271:C1424-C1437
18. Peng Q, Brown SB, Moan J, Nesland JM, Wainwright M, Griffiths J, Dixon B, Cruse-Sawyer J, Vernon D (1993) Biodistribution of a methylene blue derivative in tumor and normal tissues of rats. $\mathrm{J}$ Photochem Photobiol B 20:63-71

19. Levin RL, Degrange MA, Bruno GF, Del Mazo CD, Taborda DJ, Griotti JJ, Boullon FJ (2004) Methylene blue reduces mortality and morbidity in vasoplegic patients after cardiac surgery. Ann Thorac Surg 77:496-499 